\title{
Individual and dyadic coping in chronic pain patients
}

This article was published in the following Dove Press journal:

Journal of Pain Research

7 March 2017

Number of times this article has been viewed

\section{Andrea Burri ${ }^{1-3}$ \\ Michèle Blank Gebre ${ }^{4}$ \\ Guy Bodenmann'}

'Department of Psychology, University of Zurich, Zurich, Switzerland; ${ }^{2}$ Health and Rehabilitation Research Institute, Auckland University of Technology, ${ }^{3}$ Waitemata Pain Service, Department of Anaesthesia and Perioperative Medicine, North Shore Hospital, Auckland, New Zealand; ${ }^{4}$ Private Practice, Zurich, Switzerland
Correspondence: Andrea Burri Department of Psychology, University of Zurich, Binzmuehlestrasse 14, Box 9 , 8050 Zurich, Switzerland

Tel +4I 446357457

Fax +4I 446357552

Email a.burri@psychologie.uzh.ch
Abstract: The purpose of the current cross-sectional study was to test the associations between individual coping responses to pain, dyadic coping, and perceived social support, with a number of pain outcomes, including pain intensity, functional disability, and pain adjustment, in a sample of $\mathrm{N}=43$ patients suffering from chronic pain in Switzerland. In contrast to previous research, we were interested not only in specific pain coping but also in more general stress coping strategies and their potential influence on pain outcomes. Analyses were performed using correlation and regression analyses. "Praying and hoping" turned out to be an independent predictor of higher pain intensity and higher anxiety levels, whereas both "coping self-instructions" and "diverting attention" were associated with higher well-being, less feelings of helplessness, and less depression and anxiety. We further found a link between "focusing on and venting emotions" and "worse pain adjustment". No significant relationship between dyadic coping and social support with any of our pain outcomes could be observed. Overall, our results indicate that individual coping strategies outweigh the effects of social support and dyadic coping on pain-related outcomes and pain adjustment. However, results need to be interpreted with caution given the small sample size.

Keywords: individual coping, dyadic coping, social support, chronic pain

\section{Introduction}

Chronic pain is a common, costly, and debilitating health problem posing challenges for both health care providers and caregivers. ${ }^{1}$ Although epidemiological studies provide varying estimates of prevalence - depending on pathology, country, assessment method, and age group - a recent large-scale telephone survey across 15 European countries suggested that around 19\% of adult Europeans suffer from moderate to severe chronic pain. ${ }^{2}$ Chronic pain seriously affects the quality of the sufferers' social and working lives by causing cognitive and physical disability, immune dysfunction, depression, and social withdrawal. ${ }^{3-6}$ It has been broadly accepted that the processes underlying the development, prognosis, and treatment of chronic pain are of a complex nature and can be best explained by a biopsychosocial model, where physiological pathology, individual variation in the experience, pain-related coping and management, and the social context need to be taken into account. ${ }^{7,8}$

A number of recent experimental and clinical studies have focused on the nature and role of psychosocial factors - and more specifically on individual coping responses to pain - to identify new approaches for pain treatment, as well as on potential risk factors that influence the transition from acute to chronic pain. ${ }^{9-11}$ In terms of individual 
coping, researchers have mainly focused on the identification of adaptive and maladaptive coping strategies. ${ }^{12}$ Although there seems to be an association between certain coping strategies (e.g., acceptance) and adjustment in chronic pain patients, experts highlight methodological problems that may limit conclusions regarding the strength and nature of these relationships. ${ }^{11,13,14}$ It has therefore been recommended that future research should not only focus on the broad dichotomization of adaptive and maladaptive coping strategies but also include more specific coping and belief measures by relying less on composite constructs, therefore asking for the use of more differentiated and psychometrically sound measurement instruments. ${ }^{14}$

Another component within the "biopsychosocial" model considered crucial for pain coping is the social component that represents the influence of the patient's immediate social context. In terms of dyadic interactions, previous research has repeatedly shown how partners' responses to patients' behavioral and verbal pain communication can have direct effects on pain disability and adjustment. ${ }^{15-17}$ Similarly, a wealth of studies investigating the effects of social support on patients' pain expression and coping have repeatedly underlined the crucial influence of the immediate social environment on pain outcomes and disability. ${ }^{18-20}$ Although in a broader context study results on dyadic coping and social support consistently point toward a significant relationship between the social context and pain outcomes, findings on the role and nature of the specific mechanisms and relationships often differ from study to study and are often contradictory. ${ }^{21-23}$ Similar to research on individual coping, these inconsistencies may be due to methodological and conceptual problems, as well as operational differences that may limit study conclusions. Regarding social support, for example, some studies have reported a beneficial effect on patients' pain management, whereas others have suggested that social support may negatively impact on patients' pain coping. Most likely, these contradictory findings are due to operational differences, where one study might have focused on different modes of social support, such as emotional versus instrumental, or on different outcomes, such as pain behavior and functional behavior. Clearly, a more careful and differentiated investigation of the various sources and modes of psychosocial pain management is needed to get a better understanding on how and to what extent individual coping and the social context produce effects on pain disability and adjustment.

\section{Aims and hypotheses}

The aim of the current study was to address some of the current research gaps by more differentially exploring the relationship between individual coping, dyadic coping (i.e., partner support and joint efforts in dealing with pain), and non-partner social support with outcomes of pain, including pain disability, pain intensity, and emotional impairment (i.e., helplessness, depression, anxiety, and annoyance). In contrast to previous research, we specifically differentiated between dyadic coping and non-partner social support and further took into account a range of pain-related and general coping and belief measures, as well as different modes and aspects of dyadic coping and social support. Within these study aims, and based on previous research, we hypothesized that 1) adaptive general coping strategies, including active coping, planning, acceptance, humor, positive reinterpretation and growth, and suppression of competing activities, would be associated with lower levels of pain outcomes (i.e., pain disability, pain intensity, and emotional impairment), whereas maladaptive general coping strategies, including mental disengagement, religious coping, substance use, denial, and focus on and venting of emotions, would be associated with higher levels. 2) Supportive dyadic coping, common dyadic coping, and stress communication would be associated with lower levels of pain outcomes, whereas negative dyadic coping would be associated with higher levels. 3) Functional social support, emotional support, instrumental support, and social integration would be associated with lower levels of pain outcomes.

\section{Methods}

\section{Sample and study design}

The current study represents a correlative, cross-sectional study conducted in Switzerland in collaboration with the Rehabilitation Centre Leukerbad and the Montana Clinic in Bern. The study was promoted by the psychotherapists working at the clinics, as well as through on-site advertisements (flyers) and word-of-mouth recommendation (e.g., working staff who had been informed about the study). Patients meeting the inclusion criteria were handed out a set of questionnaires by their psychotherapist, usually at the beginning of their stay at the clinic. Interested patients were provided with a personal feedback by their psychotherapist, as well as a written feedback relating to the study results by the principal investigator at the end of the study. No incentives were given.

To be eligible to participate in the study, patients had to be aged $\geq 18$ years, suffer from pain for at least 6 months (i.e., chronic pain), currently be in a committed relationship for at least 12 months, and speak and understand German. Excluded were patients suffering from chronic pain due to a terminal illness such as cancer. Ethical approval was 
obtained from the Ethics Committee of the University of Zurich, Department of Psychology and all participants provided written informed consent for this study. The study was further in line with ethical guidelines of the Swiss Society of Psychology. In the end, a total of 43 male and female patients were included in the study, of which $\mathrm{N}=36$ were recruited via the Rehabilitation Centre Leukerbad, and $\mathrm{N}=7$ via the Montana Clinic in Bern.

\section{Materials}

All data - apart from sociodemographic information that was collected using self-constructed questions - were assessed using standardized and validated self-report questionnaires.

\section{The Coping Strategies Questionnaire (CSQ)}

The CSQ is a commonly applied instrument to assess a patient's self-rated use of cognitive and behavioral strategies to cope with pain. ${ }^{24}$ The instrument consists of 50 items, comprising the six subscales of ignoring pain, reinterpretation of pain, diverting attention, coping self-statements, catastrophizing, praying/hoping, increasing activity levels, and increasing pain behaviors. Response options are on a 7-point Likert-type scale ranging from 0 (never do that) to 6 (always do that), indicating how frequently the strategy is used to cope with pain. Each subscale yields a maximum score of 36 that can be computed by summing up all subscale-specific items. Previous validation studies have found good internal consistencies (e.g., ranging from 0.71 to 0.85 ), as well as evidence for the construct validity of the CSQ in various chronic pain populations. ${ }^{24,25}$ Studies investigating the underlying factor structure of the CSQ have yielded inconsistent and differing results. ${ }^{24,26}$ Internal consistencies in the current study were adequate to good for all subscales ( $\alpha$ ranging from 0.71 to 0.85 ) apart from increasing pain behaviors and catastrophizing, which consequently were not considered in the subsequent analyses.

\section{The Measure of Coping Styles and Strategies (COPE)} The widely applied COPE self-report questionnaire is a 60 -item measure that yields 15 subscales designed to assess a broad range of active versus avoidant coping responses. ${ }^{27}$ Coping strategies refer to the behavioral and psychological efforts that people employ to master and minimize stressful events. Subscales include positive reinterpretation and growth, mental disengagement, focus on and venting of emotions, use of instrumental social support, active coping, denial, religious coping, humor, behavioral disengagement, restraint, use of emotional social support, substance use, acceptance, suppression of competing activities, and planning. Because of the use of more specific questionnaires assessing social support (which is given in the following sections), the scales' use of instrumental social support and emotional social support were not included in this study. Ratings were made on a 5-point Likert-type scale, ranging from "I usually don't do this at all" (1) to "I usually do this a lot" (4). The initial study exploring the psychometric properties of the questionnaire has found internal consistencies ranging from $\alpha=0.45-0.92$, test-retest reliabilities ranging from 0.46 to 0.86 , and strong evidence of discriminant and convergent validity, with constructs such as hardiness, optimism, control, and self-esteem. ${ }^{27}$ Internal consistencies in the current study ranged from $\alpha=0.19$ for mental disengagement to $\alpha=0.93$ for religious coping.

\section{The Social Support Questionnaire - Short Form}

Perceived social support was measured by a 22 -item short version of the widely used German Social Support Questionnaire. ${ }^{28}$ The questionnaire produces three composite scores that reflect an individual's 1) perceived emotional support (e.g., I have friends or family members who listen to me when I want to talk about a problem), 2) perceived practical support (e.g., I can borrow anything I need from friends or neighbors), and 3) perception of social integration (e.g., there is a group of people to whom I belong to and with whom I meet regularly). The subscales' emotional support and practical support can be further summed up to produce an overall score. Response options are on a 5-point Likert-type scale ranging from "not at all" (1) to "very much" (5). Previous validation studies have reported good psychometric properties. Internal consistencies in the current sample were high with Cronbach's $\alpha$ ranging from 0.94 to 0.93 .

\section{The German Pain Coping Questionnaire (FESV-BW)}

The FESV-BW was used for the measurement of pain-related psychological impairment (i.e., helplessness, depression, anxiety, and annoyance). ${ }^{29}$ The questionnaire also assessed cognitive pain coping and behavioral pain coping, which were not used in the current study. Ratings are given on a 6-point Likert-type scale ranging from "I don't agree" (1) to "I completely agree" (6). The scales of the FESV range from 4 to 24; higher values represent a higher degree of expression of the content of the scale. A number of studies have found good psychometric properties of the scale, with high test-retest reliabilities, as well as good convergent and discriminant validity. ${ }^{29}$ Internal consistencies of the three subscales in our study ranged from $\alpha=0.80-0.84$. 


\section{The Pain Disability Index (PDI)}

The PDI is a brief instrument developed to assess self-reported, pain-related disability across seven areas of life activity: family/home, recreation, social, occupation, sexual, self-care, life support, and average.$^{30}$ Participants use a 0 (no disability) to 10 (total disability) numeric rating scale to rate the degree of impairment. A German version of the PDI has been developed by Dillman et al, ${ }^{31}$ which showed good internal consistency of the overall score $(\alpha=0.86)$ and sufficient validity.

\section{The German Pain Questionnaire (GPQ)}

To assess pain-anamnestic information, including duration and frequency of pain episodes, and typical pain intensity (in the past 3 months), several items were taken from a questionnaire developed by Leidig. ${ }^{32}$ For the latter, patients were asked to rate the current and typical pain intensity on a numerical Visual Analog Scale (VAS) ranging from 0 to 100 (no pain at all to worst pain imaginable). Both scales were then added up and divided by 2 to provide a pain intensity summary score. VAS has shown to be a useful tool in pain diagnostics, providing good sensitivity and high validity. ${ }^{33}$

\section{The Dyadic Coping Questionnaire (FDCT-N)}

The FDCT-N, a prior version of the dyadic coping inventory (DCI) was used to assess the quality and frequency of dyadic coping based on Bodenmann's ${ }^{34,35}$ systemic transactional model (STM) of coping processes in couples. It focuses on stress communication, as well as response reactions, taking into account supportive dyadic coping of the partner, common or joint dyadic coping, and negative dyadic coping. The measure consists of 39 items assessing three components of the STM: stress communication (i.e., how often the partners solicit support from each other when they are feeling stressed), the partner's dyadic coping responses to the other's stress signals (i.e., support responses - what the partner usually does when noticing that the other is experiencing stress), and mutual or common dyadic coping (i.e., what the partners do together to manage stress). Moreover, the scale provides two additional items to evaluate the efficacy of dyadic coping (item 40) and partners' satisfaction with it. All 41 items are responded to on a Likert-type 5-point scale ranging from "never" to "very often". The psychometric properties of the questionnaire have been examined and evaluated as very good. ${ }^{34}$ Internal consistencies of the DCI in the current study ranged from $\alpha=0.74$ to 0.90 .

\section{Statistical analyses}

Distributional properties of the different subscales were checked by visual inspection and Kolmogorov-Smirnov test. Non-normal distributed scales (the COPE scales humor, substance abuse, and restraint, the CSQ subscale ignoring pain) were either root, square root, or log transformed. First, to examine the relationship between our variables of interest, bivariate Pearson's correlation analyses were conducted. Bonferroni correction was used to account for the effects of multiple testing. Second, to investigate the independent effects of the various individual coping strategies, stepwise forward multiple linear regression models were conducted separately for the dependent pain outcome variables (i.e., pain disability, pain intensity, and pain-related helplessness, depression, anxiety, and annoyance). Only the COPE and CSQ subscales showing internal consistencies of $\alpha>0.60$ were included in the analyses; therefore, the CSQ subscale of increasing pain behavior and the COPE subscale of mental disengagement, active coping, and restraint were not included. For all analyses, a $p$-value of $<0.05 \%$ was considered statistically significant, unless stated otherwise. Data handling and analyses were performed using SPSS version 12 (IBM Corp., Armonk, NY USA).

\section{Results}

\section{Sample and pain characteristics}

A total of 33 female and 10 male patients, aged between 27 and 71 years $(M=51.8, \mathrm{SD}=10.8)$ were included in the current study (Table 1). The average relationship duration was 24.2 years ( $\mathrm{SD}=12.8$; range: $3-48)$, and 35 patients were married. The chronic pain diagnoses showed some heterogeneity with fibromyalgia (FM) being the most common complaint (16 individuals), followed by back and neck pain (nine) and somatoform pain (eight). Other complaints included arthritis and osteoporosis. A total of 10 patients reported more than one pain diagnosis. The average duration of chronic pain was 14.2 years $(\mathrm{SD}=12.8$; range: 0.6-47 years). A total of 32 individuals reported daily pain, eight had pain on several days of the week, and two reported pain approximately once a week. The average pain intensity was $M=70$ ( $\mathrm{SD}=16$; range: $13-100)$ with 11 (35\%) patients complaining about a very high pain intensity $(80-100$ on the VAS), and two-thirds (65\%) about a high pain intensity (VAS, 60-80). Pain disability was perceived lowest in the area of self-care and life support. Across all other areas, disability was perceived to be more or less equal with an average of $M=4.9$ (SD = 2; range: $0.9-8.1$ ). In terms of psychological well-being, pain-related helplessness and depression $(M=$ 3.3; $\mathrm{SD}=1.1$; range: $1-5.4)$ was found to be highest compared to anxiety $(M=3.0 ; \mathrm{SD}=1.2$; range: $1-5.3)$ and annoyance $(M=2.9 ; \mathrm{SD}=1.2$; range: $1-5.8)$. 
Table I Sociodemographic information of a sample of $N=43$ pain patients

\begin{tabular}{|c|c|}
\hline Variable & Percentage \\
\hline \multicolumn{2}{|l|}{$\overline{\text { Gender }}$} \\
\hline Female & 76.7 \\
\hline Male & 23.3 \\
\hline \multicolumn{2}{|l|}{ Age (years) } \\
\hline $20-29$ & 2.3 \\
\hline $30-39$ & 9.3 \\
\hline $40-49$ & 25.6 \\
\hline $50-59$ & 41.9 \\
\hline $60-69$ & 16.3 \\
\hline $70-79$ & 4.7 \\
\hline \multicolumn{2}{|l|}{ Marital status } \\
\hline Single & 4.7 \\
\hline Married & 81.4 \\
\hline Divorced & 11.6 \\
\hline Widowed & 2.3 \\
\hline \multicolumn{2}{|l|}{ Relationship duration (years) } \\
\hline $0-9$ & 16.3 \\
\hline $10-19$ & 20.9 \\
\hline $20-29$ & 30.2 \\
\hline $30-39$ & 16.3 \\
\hline $40-49$ & 16.3 \\
\hline \multicolumn{2}{|l|}{ Living situation } \\
\hline With partner & 51.2 \\
\hline With partner and child & 46.5 \\
\hline Alone with child & 2.3 \\
\hline \multicolumn{2}{|c|}{ Education (highest achieved, Ausbildung) } \\
\hline Primary school & 20.9 \\
\hline Secondary school & 7 \\
\hline Apprenticeship & 51.2 \\
\hline Gymnasium/college & 14 \\
\hline University & 7 \\
\hline \multicolumn{2}{|c|}{ Employment (full versus part-time), \% } \\
\hline 0 & 53.5 \\
\hline 10 & 2.3 \\
\hline $30-40$ & 4.7 \\
\hline $50-60$ & 16.3 \\
\hline $70-80$ & 9.3 \\
\hline $90-100$ & 14.0 \\
\hline
\end{tabular}

\section{Bivariate correlation analyses}

\section{Individual coping}

Significant relationships between the individual painrelated coping strategies "self-instructions" and "diverting attention" with helplessness and depression $(r=-0.45$ and -0.42 , respectively; $p<0.001$ for both) and anxiety could be observed ( $r=-0.31, p<0.05$ and $-0.25, p<0.1$; Table 2). In contrast, "praying and hoping" was associated with higher levels of pain disability $(r=0.20, p<0.1)$, higher pain intensity $(r=0.41, p<0.001)$, and more anxiety $(r=0.36$, $p<0.005)$. In terms of general individual coping strategies, the maladaptive strategies of "focus and venting of emotions" were significantly associated with higher levels of helplessness and depression $(r=0.50$ and $0.52, p<0.001$ for both), anxiety ( $r=0.46$ and $0.57, p<0.001$ for both) and annoyance ( $r=0.6, p<0.001$ for focus on and venting of emotions; Table 2). Only the adaptive strategy of "acceptance" was associated with significantly less helplessness and depression $(r=-0.31, p<0.001)$, anxiety $(r=-0.40$, $p<0.001)$, and annoyance $(r=-0.44, p<0.001)$. Apart from "religious coping" $(r=0.26, p<0.001)$, no coping strategy was associated with pain intensity. Similarly, for pain disability, only statistical trends (suppression of competing activities and focus on and venting of emotions) could be observed (Table 2).

\section{Dyadic coping}

In terms of dyadic coping, no statistically significant correlations could be found, but several trends were observed. Partner's "encouragement and distraction", for example, as well as supportive dyadic coping and stress communication, were marginally associated with higher pain disability, and negative dyadic coping was associated with higher painrelated anxiety and annoyance ( $r$ 's ranging from 0.21 to 0.25 ; $p<0.1$ for all; Table 2). None of the dyadic coping strategies showed any relationship with pain intensity or pain-related helplessness and depression.

\section{Social support}

Similar to dyadic coping, no statistically significant correlations between social support and any of the pain outcomes could be detected apart from two statistical trends, with chronic pain patients with more "social integration" also reporting less pain disability and less pain-related anxiety $(r=-0.20$ and -0.21 , respectively; $p<0.1$ for both; Table 2 ).

\section{Stepwise multiple regression analyses} Pain disability

In the stepwise regression models, none of the pain-related or general coping strategies (CSQ, COPE), nor any aspects of partner or social support, turned out to be an independent predictor of pain disability (Table 3 ).

\section{Pain intensity}

The pain-related coping strategy of praying and hoping turned out to be the sole independent predictor of higher pain intensity ( $\beta=5.5, p<0.01$ ), explaining $13 \%$ of the variation (Table 3 ).

Helplessness and depression, anxiety, and annoyance Coping self-instructions and diverting attention were associated with less feelings of helplessness and depression ( $\beta=-0.30, p<0.05$ and $\beta=-0.56, p<0.001$, respectively), 
Table 2 Results from the correlational analyses between individual coping, dyadic coping, and social support and various pain outcomes

\begin{tabular}{|c|c|c|c|c|c|}
\hline & Pain disability & Pain intensity & Helplessness and depression & Anxiety & $\overline{\text { Annoyance }}$ \\
\hline \multicolumn{6}{|l|}{ Individual coping (CSQ and COPE) } \\
\hline Ignoring pain & $-0.23^{*}$ & -0.10 & -0.03 & -0.06 & $-0.27^{* k}$ \\
\hline Coping self-instructions & -0.17 & 0.04 & $-0.45^{\text {wew*k }}$ & $-0.31^{* *}$ & $-0.21^{*}$ \\
\hline Praying/hoping & $0.20^{*}$ & $0.41^{\text {*opk }}$ & 0.17 & $0.36^{*+* k}$ & 0.19 \\
\hline Diverting attention & 0.15 & 0.17 & $-0.42^{* * * k}$ & $-0.25^{*}$ & 0.06 \\
\hline Reinterpretation of pain & -0.05 & -0.08 & -0.09 & -0.06 & 0.05 \\
\hline Increasing activity levels & 0.12 & 0.10 & $-0.22^{*}$ & -0.02 & 0.16 \\
\hline CSQ summary score & -0.12 & -0.04 & $-0.37^{\text {topk }}$ & $-0.27^{* *}$ & -0.14 \\
\hline Planning & -0.05 & -0.16 & 0.00 & -0.07 & 0.07 \\
\hline Suppression of competing activities & $0.22^{*}$ & 0.08 & $0.25^{*}$ & 0.10 & $0.23^{*}$ \\
\hline Positive reinterpretation and growth & 0.18 & 0.07 & $-0.22^{*}$ & -0.12 & $-0.20^{*}$ \\
\hline Acceptance & -0.07 & -0.03 & $-0.31^{* *}$ & $-0.40^{\text {sek }}$ & $-0.44^{*+*}$ \\
\hline Humor & -0.09 & -0.06 & 0.01 & 0.07 & -0.00 \\
\hline Substance use & -0.09 & 0.04 & 0.19 & 0.18 & $0.34^{* k}$ \\
\hline Focus on and venting of emotions & $0.22^{*}$ & -0.05 & $0.52^{\text {*wek }}$ & $0.57^{\text {wikk }}$ & $0.64^{*+*+* *}$ \\
\hline Denial & -0.00 & 0.16 & 0.13 & $0.22^{*}$ & 0.18 \\
\hline Religious coping & 0.10 & $0.26^{* *}$ & 0.06 & $0.20^{*}$ & 0.14 \\
\hline COPE summary score & -0.11 & -0.19 & $-0.4 I^{\text {*owk }}$ & $-0.47^{\text {wotk }}$ & $-0.4 I^{* * * *}$ \\
\hline \multicolumn{6}{|l|}{ Dyadic coping (FDCT) } \\
\hline Supportive dyadic coping of the partner & $0.25^{*}$ & 0.00 & 0.01 & -0.12 & 0.02 \\
\hline Supportive dyadic coping of the patient & 0.17 & 0.12 & -0.08 & -0.06 & -0.03 \\
\hline Mutual dyadic coping & 0.17 & 0.01 & -0.10 & -0.14 & -0.09 \\
\hline Stress communication & $0.22^{*}$ & -0.15 & 0.07 & 0.03 & 0.14 \\
\hline Negative dyadic coping & 0.03 & -0.10 & 0.15 & $0.21^{*}$ & $0.22^{*}$ \\
\hline FDCT summary score & $0.25^{*}$ & 0.00 & 0.01 & -0.12 & 0.02 \\
\hline \multicolumn{6}{|l|}{ Social support } \\
\hline Emotional support & -0.03 & 0.13 & -0.04 & -0.17 & -0.15 \\
\hline Practical support & -0.14 & -0.04 & 0.02 & -0.15 & -0.14 \\
\hline Social Integration & $-0.20^{*}$ & -0.10 & -0.05 & $-0.21^{*}$ & -0.17 \\
\hline Social support summary score & -0.07 & 0.07 & -0.02 & -0.17 & -0.15 \\
\hline
\end{tabular}

Notes: ${ }^{*} p$-value $<0.1 ;{ }^{* *} p$-value $<0.05 ;{ }^{* * * *} p$-value $<0.01$; ${ }^{* *+k * *} p$-value $<0.001$.

Abbreviation: CSQ, Coping Strategies Questionnaire.

Table 3 Results from the multivariate regression model

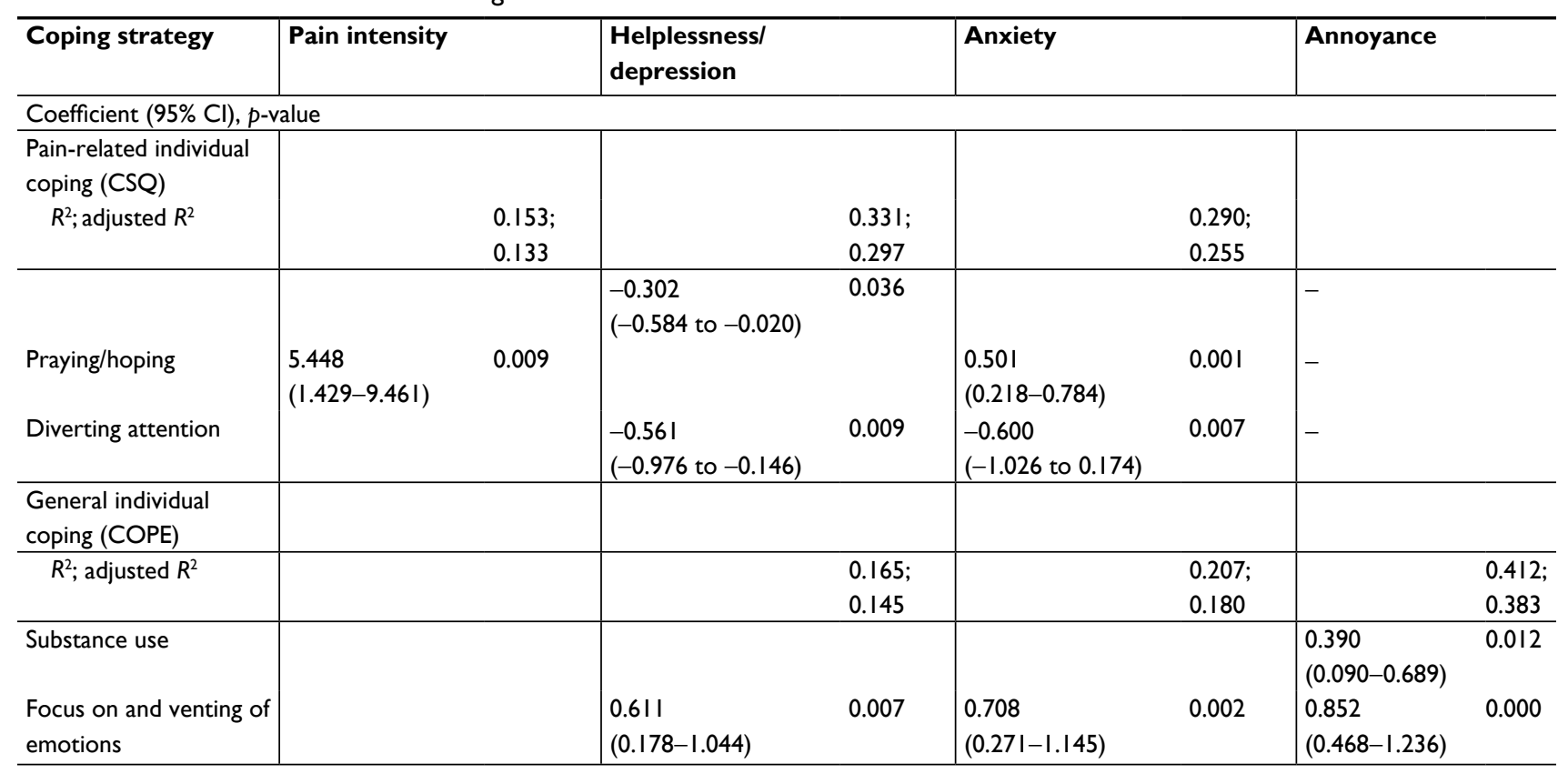

Note: Only significant results are given.

Abbreviations: $\mathrm{Cl}$, confidence interval; CSQ, Coping Strategies Questionnaire. 
together explaining $33 \%$ of outcome variation (Table 3 ). "Focusing on and venting emotions", however, seem to lead to more feelings of helplessness and depression $(\beta$ $=0.61, p<0.01$ ), explaining $16 \%$ of the variance. It also turned out to be an independent predictor of higher levels of anxiety $(\beta=0.708, p<0.001)$ and annoyance $(\beta=0.852$, $p<0.001)$. Together with "substance abuse" $(\beta=0.39, p$ $<0.05)$, it explained $41 \%$ of the variance in annoyance (Table 3 ). In addition to focusing on and venting emotions, the pain-related coping strategies of praying and hoping and diverting attention were also related to anxiety, with the first one leading to higher levels $(\beta=0.51, p=0.001)$, and the latter one to lower levels $(\beta=-0.60, p<0.005)$, together explaining $33 \%$ of the variance in anxiety. No significant explanation of variance by social support or dyadic coping could be detected.

\section{Discussion}

The purpose of the current study was to investigate the links between individual coping, dyadic coping, and social support with a set of pain outcomes to identify potential predictors of chronic pain adjustment that might serve as a basis for more clearly focused and targeted approaches to multifaceted pain management. In contrast to previous research, we were interested not only in specific pain coping but also in more general stress coping strategies and their potential influence on pain outcomes. According to our central hypothesis, we postulated that apart from pain-specific coping, individual coping in general, as well as dyadic coping and social support, would be associated with well-being and pain adjustment in chronic pain patients, with adaptive coping strategies and functional partner support leading to higher well-being and maladaptive coping strategies and dysfunctional partner support showing impairing effects on pain adjustment and well-being.

\section{Pain-specific and general individual coping}

Overall, our initial hypotheses were only partially supported. In terms of pain-specific coping strategies, praying and hoping turned out to be an independent predictor of higher pain intensity and higher anxiety levels, whereas coping self-instructions and diverting attention were both associated with higher well-being with less feelings of helplessness and depression and anxiety. These findings are somewhat in accordance with numerous previous studies repeatedly demonstrating a relationship - though not always consistent in terms of the negative versus positive nature of this relationship - between praying and hoping and pain adjustment. ${ }^{36-39}$ Although we were able to replicate a negative association in our study, the clinical value of this finding remains unclear. Boothby et al, ${ }^{37}$ for example, suggested that people may have the tendency to hope and pray more often when they are doing particularly badly, rather than praying/hoping leading to lower well-being. Clearly, longitudinal studies assessing coping strategies and their importance in the transition from acute to chronic pain are needed to address this question and to shed light on the nature and direction of this link. Similarly, mixed are the previous insights gained about the usefulness of coping self-instructions. Although coping self-instructions (e.g., I tell myself that I can handle this pain) are often taught in multidisciplinary treatment settings, it has been argued that these strategies remain inefficient under certain circumstances, for example, when reported pain intensity levels are high. ${ }^{40,41}$ Furthermore, the effects of coping self-instructions may be mediated by other psychological factors such as self-efficacy and similar psychological traits and beliefs. ${ }^{42}$ Clearly, a better understanding of such potential mediators is needed to understand the potential role and efficacy of coping self-instruction in the management of chronic pain.

Our finding of a positive association of diverting attention adds to the numerous inconsistent study findings. ${ }^{37,40,43-45}$ In our study, diverting attention led to less feelings of helplessness and depression, as well as to less pain-related anxiety. It has, however, been suggested that the link might be moderated by pain characteristics such as intensity and acuity. ${ }^{44,45}$ Similarly, it is possible that patients with a better psychological setup have less problems in applying this specific coping strategy.

Noteworthy is the fact that we were able to observe significant links not only between pain-specific coping strategies but also between more general coping tendencies and pain outcomes. While a large number of studies have investigated the role of pain-related coping strategies, the amount of research focusing on the importance of general coping strategies in the management of chronic pain has been smaller. In this study, we found that the more frequent use of the general coping strategies of focusing on and venting emotions turned out to be associated with poorer pain adjustment, especially in terms of helplessness and depression, anxiety, and annoyance. According to our results, emotion-oriented coping strategies seem to be less useful in the management of pain-associated emotional expression, whereas they did not seem to be linked with pain perception and expression per se.

In addition, a relationship between substance abuse and annoyance could be detected. This is in accordance with our hypothesis suggesting that maladaptive general coping strategies would be associated with poorer pain-related health outcomes. 


\section{Social support and dyadic coping}

Contrary to our hypothesis, no significant relationship between dyadic coping - neither positive nor negative and any of our pain outcomes could be observed. The same picture emerged for all facets of social support, including emotional and practical support, as well as perception of social integration. While these might represent true findings, it is equally possible that the relatively small sample size might have lead to low statistical power which would explain some of the statistical trends that we were able to observe, which however, did not reach statistical significance. One such trend, for example, showed that individuals who were better integrated socially complained about less pain disability and pain-related anxiety. This is somewhat in accordance with findings from a study by Jamison and Virts ${ }^{19}$ who found that chronic pain patients $(\mathrm{N}=521)$ who lived closer to their family members and had a bigger family circle showed more adequate pain management compared to patients with a smaller family network. Similarly, findings from a study by Evers et $\mathrm{al}^{22}$ conducted on 91 arthritis patients suggested that a bigger social network (therefore, better social integration) showed a significant link with pain duration and better mobility 1 year after baseline assessment. Overall, better social integration seems to have a more longterm improving effect on the functional impairment that chronic pain can cause.

Interestingly, in terms of dyadic coping, supportive dyadic coping, as well as "encouragement and distraction" was associated with more pain disability. This is consistent with findings from studies resting on the operant behavioral model of pain suggesting that partners who are too helpful and sympathetic may provoke an increase in pain and disability in their partner. ${ }^{46-48}$ According to our hypothesis, negative dyadic coping showed a marginal association with more pain-related anxiety and annoyance. Only one study so far has investigated the effects of supportive and negative dyadic coping, according to the classification proposed by Bodenmann. ${ }^{49}$ This study has mainly focused on the association between supportive dyadic coping and pain outcomes, whereas negative dyadic coping has not been investigated so far. Previous studies exploring the relationships between punishing partner behavior (e.g., critic and anger) on pain adjustment have, however, found significant effects on worse psychological well-being and increased pain and disability. ${ }^{50}$ Larger studies are needed to confirm these results.

\section{Pain-related outcomes}

While the assessed coping variables were able to jointly explain around $33 \%$ of variation in comorbid helplessness and depression, and even $41 \%$ of the variance in annoyance, none of the included individual nor dyadic coping strategies explained any of the variation in reported pain disability and only little (13\%) in pain intensity. These findings highlight the fact that other - within the context of this study not assessed - biopsychosocial factors may play a role in successful pain management or that they mediate the relationship between coping and pain adjustment. Such potential moderators or causative factors should be the target of future studies investigating the predictors of adjustment to chronic pain, eventually leading to a more holistic understanding of the mechanisms underlying chronic pain expression and management.

\section{Limitations}

The current results have to be interpreted in view of a number of limitations. Due to the cross-sectional nature of the study design, we were only able to report on associations without any information regarding the direction of causality. Our chronic pain patient group was relatively heterogeneous, and it is therefore possible that different coping strategies may produce different outcomes depending on the condition/diagnosis. Future studies should consider investigating individual and dyadic coping, as well as the influence of social support in more homogenous chronic pain populations. Furthermore, bigger sample sizes should be warranted to produce bigger effect sizes and to ensure higher statistical power. Due to the small sample size of our study, our results can mainly be viewed as trends and should be interpreted with caution, especially in terms of the regression analyses, which were most likely underpowered. Therefore, future studies should make an extra effort in using larger datasets. Similarly, because of the small sample and low power, we were not able to control for the effects of certain factors such as relationship duration which could have a potential moderating effect on our investigated associations and the various coping strategies and on social support. Finally, results cannot be extrapolated to other ethnicities or races since research has consistently highlighted the existence of race differences in some pain coping strategies, such as praying and hoping (e.g., more often used in African Americans compared to Caucasians). ${ }^{51,52}$

\section{Conclusion}

Our results indicate that individual coping strategies outweigh the effects of social support and dyadic coping on pain-related outcomes and pain adjustment. Findings further show that apart from pain-related individual coping, more general coping strategies can have a significant impact on a patient's well-being and pain perception. Future studies should consider more in-depth exploration of individual 
coping strategies and their role in pain management. In terms of clinical practice, our results suggest that general coping strategies should be assessed as part of the patient evaluation and that maladaptive strategies should be minimized.

\section{Disclosure}

AB reports an Ambizione personal career fellowship by the Swiss National Science Foundation. She also acknowledges a research grant support from the Swisslife Jubiläumsstiftung. The other authors report no conflicts of interest in this work.

\section{References}

1. Institute of Medicine. Relieving Pain in America: A Blueprint for Transforming Prevention, Care, Education, and Research. Washington, DC: The National Academies Press; 2011.

2. Breivik H, Collet B, Ventafridda V, Cohen R, Gallacher D. Survey of chronic pain in Europe: prevalence, impact on daily life, and treatment. Eur J Pain. 2006;10(4):287-333.

3. Zhu K, Devine A, Dick IM, Prince RL. Association of back pain frequency with mortality, coronary heart events, mobility, and quality of life in elderly women. Spine. 2007;32(18):2012-2018.

4. Tan G, Jensen MP, Thornby J, Sloan PA. Negative emotions, pain and functioning. Psychol Serv. 2008;5:26-35.

5. De Heer EW, Gerits M, Beekman A, et al. The Association of Depression and Anxiety with Pain: a study from the NESDA. PLoS One. 2014;9(10):e106907.

6. Marchand F, Perretti M, McMahon SB. Role of the immune system in chronic pain. Nat Rev Neurosci. 2005;6(7):521-532.

7. Gatchel RJ, Peng YB, Peters ML, et al. The biopsychosocial approach to chronic pain: scientific advances and future directions. Psychol Bull. 2007;133:581-624.

8. Gatchel RJ. Clinical Essentials of Pain Management. Washington, DC: American Psychological Association; 2005.

9. DasMahapatra P, Chiauzzi E, Pujol LM, Los C, Trudeau KJ. Mediators and moderators of chronic pain outcomes in an online self-management program. Clin J Pain. 2015;31(5):404-413.

10. Dysvik E, Kvaloy JT, Natvig GK. The effectiveness of an improved multidisciplinary pain management programme: a 6- and 12-month follow-up. J Adv Nurs. 2012;68(5):1061-1072.

11. Kohl A, Rief W, Globiewski JA. Acceptance, cognitive restructuring, and distraction as coping strategies for acute pain. J Pain. 2013;14(3): 305-315.

12. Tan G, Teo I, Anderson KO, Jensen MP. Adaptive versus maladaptive coping and beliefs and their relation to chronic pain adjustment. Clin J Pain. 2011;27(9):769-774.

13. Dysvik E, Natvig GK, Eikeland OJ, Lindstrom TC. Coping with chronic pain. Int J Nurs Stud. 2005;42(3):297-305.

14. Jensen MP, Turner JA, Romano JM. Chronic pain coping measures: individual vs. composite scores. Pain. 1992;51(3):273-280.

15. Cano A, Barterian JA, Heller JB. Empathic and nonempathic interaction in chronic pain couples. Clin J Pain. 2008;24(8):678-684.

16. Geisser ME, Cano A, Leonard MT. Factors associated with marital satisfaction and mood among spouses of persons with chronic back pain. J Pain. 2005;6(8):518-525.

17. Leonard MT, Cano A, Johansen AB. Chronic pain in a couples context: a review and integration of theoretical models and empirical evidence. J Pain. 2006;7(6):377-390.

18. Lopez-Martinez AE, Esteve-Zarazaga R, Ramirez-Maestre C. Perceived social support and coping responses are independent variables explaining pain adjustment among chronic pain patients. J Pain. 2008;9(4):373-379.

19. Jamison R, Virts K. The influence of family support on chronic pain. Behav Res Ther. 1990;28:283-287.

20. Harris S, Morley S, Barton SB. Role loss and emotional adjustment in chronic pain. Pain. 2003;105(1-2):363-370.
21. Gil KM, Keefe FJ, Crisson JE, Van Dalfsen PJ. Social support and pain behavior. Pain. 1987;29(2):209-217.

22. Evers AW, Kraaimaat FW, Geenen R, Jacobs JW, Bijlsma JW. Pain coping and social support as predictors of long-term functional disability and pain in early rheumatoid arthritis. Behav Res Ther. 2003;41(11): 1295-1310.

23. Serra J, Boxados A, Perez C, Clemente M. Perceived social support and chronic pain: 14AP6-8. Eur J Anaest. 2001;28:205-209.

24. Rosenstiel A, Keefe FJ. The use of coping strategies in chronic low back pain patients: relationship to patient characteristics and current adjustment. Pain. 1983;17(1):33-44.

25. Burckhardt CS, Henriksson C. The Coping Strategies Questionnaire Swedish version: evidence of reliability and validity in patients with fibromyalgia. Scand J Behav Ther. 2001;30(3):97-107.

26. Riley JL, Robinson ME, Geisser ME. Empirical subgroups of the Coping Strategies Questionnaire-revised: a multisample study. Clin J Pain. 1999;15(2):111-116.

27. Carver CS, Scheier MF, Weintraub JK. Assessing coping strategies: a theoretically based approach. J Pers Soc Psychol. 1989;56(2):267-283.

28. Fydrich T, Bastian H, Flor H. Rolle der Familie und sozialer Unterstützung bei chronischen Schmerzen. [Role of the family and social support in chronic pain]. In: Basler HD, Franz C, Kröner-Herwig B, Rehfisch HP, editors. Psychologische Schmerztherapie: Grundlagen, Diagnostik, Krankheitsbilder, Schmerzpsychotherapie. Berlin: Springer; 2004:99-118. German.

29. Geissner E. FESV. Fragebogen zur Erfassung der Schmerzverarbeitung. [Questionnaire for the recording of pain processing]. Göttingen: Hogrefe; 2001. German.

30. Pollard CA. Preliminary validity study of Pain Disability Index. Perc Mot Skills. 1984;59:974.

31. Dillmann U, Nilges P, Saile H. Behinderungseinschätzung bei chronischen Schmerzpatienten. [Disability assessment in chronic Pain patients]. Der Schmerz. 1994;8:100-110. German.

32. Leidig U. Chronischer Schmerz und Partnerschaft. [Chronic pain and partnership]. Aachen: Shaker; 1996. German.

33. Nilges P, Wichmann-Dorn E. Schmerzanamnese. In: Basler HD, Franz C, Kröner-Herwig B, Rehfisch HP, editors. Psychologische Schmerztherapie: Grundlagen, Diagnostik, Krankheitsbilder, Schmerzpsychotherapie. [Psychological Pain Therapy: basics, diagnostics, disease pictures, pain psychotherapy]. Berlin: Springer; 2011;243-270. German.

34. Bodenmann G. Dyadisches Coping Inventar (DCI). Bern, Switzerland: Huber; 2008.

35. Bodenmann G. Dyadic coping - a systemic-transactional view of stress and coping among couples: theory and empirical findings. Eur Rev Appl Psychol. 1997;47:137-140.

36. Ashby JS, Lenhart RS. Prayer as a coping strategy for chronic pain patients. Rehab Psychol. 1994;39:205-209.

37. Boothby JL, Thorn BE, Stroud MW, Jensen MP. Coping with pain. In: Gatchel RJ, Turk DC, editors. Psychosocial Factors in Pain. Critical Perspectives. New York, NY: The Guilford Press; 1999:S.343-359.

38. Baetz M, Bowen R. Chronic pain and fatigue: associations with religion and spirituality. Pain Res Manag. 2008;13(5):383-388.

39. Dezutter J, Krysinska K, Corveleyn J. Religious factors in pain management: a psychological perspective. J Anesthe Clinic Res. 2011;4:274.

40. Jensen MP, Karoly P. Pain-specific beliefs, perceived symptom severity, and adjustment to chronic pain. Clin J Pain. 1992;8(2):123-130.

41. Jensen MP, Turner JA, Romano JM. Changes in beliefs, catastrophizing, and coping are associated with improvement in multidisciplinary pain treatment. J Consult Clin Psychol. 2001;69(4):655-662.

42. Haythornthwaite J, Menefee L, Heinberg L, Clark M. Pain coping strategies predict perceived control over pain. Pain. 1998;77:33-39.

43. Elomaa MM, de C Williams AC, Kalso EA. Attention management as a treatment for chronic pain. Eur J Pain. 2009;13(19):1062-1067.

44. Affleck G, Urrows S, Tennen H, Higgins P. Daily coping with pain from rheumatoid arthritis: patterns and correlates. Pain. 1992;51(2):221-229.

45. Schmitz U, Saile H, Nilges P. Coping with chronic pain: flexible goal adjustment as an interactive buffer against pain-related distress. Pain. 1996;67(1):41-51. 
46. Cano A, Gillis M, Heinz W, Geisser M, Foran H. Marital functioning, chronic pain, and psychological distress. Pain. 2004;107(1-2):99-106.

47. Burns JW, Gerhart JL, Post KM, et al. The communal coping model of pain catastrophizing in daily life: a within-couples daily diary study. J Pain. 2015;16(11):1163-1175.

48. Romano JM, Jensen MP, Turner JA, Good AB, Hops H. Chronic pain patient-partner interactions: further support for a behavioral model of chronic pain. Behav Ther. 2000;31:415-440.

49. Bodenmann G. Stress und Coping bei Paaren. [Stress and coping with couples]. Göttingen: Hogrefe; 2000. German.
50. Schwartz L, Ehde DM. Couples and chronic pain. In: Schmaling KB, Goldman Sher T, editors. The Psychology of Couples and Illness: Theory, Research and Practice. Washington, DC: American Psychological Association; 2000:191-216.

51. Dunn KS, Horgas AL. Religious and nonreligious coping in older adults experiencing chronic pain. Pain Manag Nurs. 2004;5(1):19-28.

52. Edwards RR, Moric M, Husfeldt B, Buvanendran A, Ivank-ovich O. Ethnic similarities and differences in the chronic pain experience: a comparison of African American, Hispanic, and White patients. Pain Med. 2005; 6(1):88-98.

\section{Publish your work in this journal}

The Journal of Pain Research is an international, peer reviewed, open access, online journal that welcomes laboratory and clinical findings in the fields of pain research and the prevention and management of pain. Original research, reviews, symposium reports, hypothesis formation and commentaries are all considered for publication.
Dovepress

The manuscript management system is completely online and includes a very quick and fair peer-review system, which is all easy to use. Visit http://www.dovepress.com/testimonials.php to read real quotes from published authors. 